\title{
Mutação do gene p53 induzindo predisposição hereditária ao câncer: relato de um caso da síndrome de Li-Fraumeni*
}

\section{P53 gene mutation inducing hereditary cancer predisposition: case report of Li-Fraumeni syndrome*}

\author{
Fernanda Nunes Pinto ${ }^{\star \star}$, Fernanda Vilas Boas Prudente ${ }^{\star \star}$, Marina Sahade \\ Gonçalves **, Priscilla Domene Vaccaro Silva**, Auro Del Giglio***
}

Pinto FN, Prudente FVB, Gonçalves MS, Silva PDV, Giglio A. Mutação do Gene p53 induzindo predisposição hereditária ao câncer: relato de um caso da síndrome de Li-Fraumeni. Rev Med (São Paulo) 2002 jan./dez.;81(1/4):42-6.

RESUMO: A Síndrome de Li-Fraumeni é uma síndrome de predisposição familiar ao câncer, caracterizada pela presença de múltiplos tumores, tais como sarcomas, carcinomas de mama, tumores cerebrais e leucemia. O caso relatado é de uma paciente feminina de 37 anos, que apresenta uma significativa história familiar de câncer, bem como história pessoal de seis diferentes tumores primários (um de cólon, um nevus displásico, um de ovário e três de mama). O seqüenciamento do gene supressor de tumor p53 em seus linfócitos presentes no sangue periférico revelou uma mutação do aminoácido triptofano (TGG) para um códon de parada prematuro (TAG), no nucleotídeo 437 do códon 146 do exon 5 deste gene. As implicações clínicas, preventivas e éticas deste caso são também abordadas.

DESCRITORES: Neoplasias primárias múltiplas/genética; Proteína P53/genética; Mutação/genética.

\section{INTRODUÇÃO}

O câncer é uma patologia de etiologia multifatorial, resultante principalmente de alterações genéticas, de fatores ambientais e do estilo de vida7. O descobrimento de genes relacionados ao câncer humano - oncogenes - permitiu uma maior compreensão das alterações genéticas associadas a transformações malignas das células ${ }^{17,19}$. Tais alterações afetam principalmente três classes de genes reguladores: os promotores do crescimento (proto-oncogenes), os inibidores do crescimento celular (genes supressores de tumor) e os genes que regulam o programa de morte celular (apoptose) ${ }^{4}$.

De fato, a principal alteração genética encontrada no câncer humano é a mutação do gene supressor de tumor p53 ${ }^{5,10,13,21}$, presente em pouco mais de $50 \%$ dos tumores ${ }^{3}$. O gene p53 localiza-se no braço curto do cromossomo humano $17^{12}$, e codifica a síntese de uma fosfoproteína nuclear expressa em níveis basais em todas as células normais ${ }^{11}$. A proteína p53 desacelera a progressão do ciclo celular e permite, portanto, que a célula tenha mais tempo para reparar o DNA antes de entrar na fase S ou mitose. Entretanto, quando a reparação dos danos do DNA não for eficiente, o p53 pode estimular a morte celular programada (apoptose) da célula. Estes efeitos contribuem para a proteção do organismo contra o acúmulo de

* Prêmio Oswaldo Cruz (Relato de Caso) - XXI COMU Congresso Médico Universitário da FMUSP.

** Acadêmicos da Faculdade de Medicina do ABC.

*** Titular das Disciplinas de Oncologia e Hematologia da Faculdade de Medicna do ABC (orientador).

Endereço para correspondência : Marina Sahade Gonçalves. R. Passo da Pátria, 1240, Ap. 82, CEP: 05085-000, São

Paulo, SP.e-mail: marinasg@zipmail.com.br 
mutações genéticas, dificultando assim a ocorrência de células geneticamente instáveis e com predisposição à transformação ma ligna ${ }^{16}$. Entretanto, havendo uma alteração funcional do p53, não há reparo eficiente do DNA, e as mutações acumulam-se nas células em divisão, que podem então, em um dado momento, sofrer transformação maligna ${ }^{16}$.

$\mathrm{Na}$ formação da maioria dos tumores, as mutações de inativação de ambos os alelos do gene p53 ocorrem de modo aleatório, sendo necessário, portanto, dois eventos distintos na célula somática. Com menor freqüência, alguns indivíduos herdam um alelo p53 mutante, necessitando, dessa forma, de apenas um evento que afete a única cópia normal existente deste gene para a perda da atividade do gene supressor de tumor. Esses indivíduos são portadores de uma síndrome rara, conhecida como Síndrome de Li-Fraumeni, e possuem uma probabilidade vinte e cinco vezes maior de desenvolver tumores malignos ${ }^{6}$, tais como sarcomas, tumores de mama, leucemias, linfomas, entre outros 22 .

Relatamos a seguir um interessante caso da Síndrome de Li-Fraumeni.

\section{RELATO DO CASO}

Em 1992, paciente do sexo feminino, 37 anos, foi diagnosticada com adenocarcinoma de cólon transverso, $\mathrm{T}_{3} \mathrm{~N}_{0} \mathrm{M}_{0}$ (Dukes $\mathrm{C}$ ), cujo tratamento foi a ressecção cirúrgica. No ano seguinte, em 1993, realizou uma biópsia excisional de um nevus displásico em quadril direito.

Em exames de rotina realizados em 1994, apresentou novo tumor primário, desta vez no ovário, sendo que o exame anatomopatológico constatou um cistoadenocarcinoma mucinoso de ovário, grau 3, e a paciente foi submetida a uma salpingooforectomia bilateral, juntamente com histerectomia.
No ano seguinte, em 1995, foram encontradas em mamografia micro calcificações em mama esquerda, cuja biópsia excisional constatou carcinoma ductal in situ. A paciente iniciou tratamento preventivo com tamoxifeno, fazendo uso deste por um período de dois anos. Em 1997, após detecção de novas calcificações em mama esquerda, foi constatado por biópsia um carcinoma ductal in situ em quadrante inferior lateral, estadio I. A paciente foi então submetida à quadrantectomia de mama esquerda e radioterapia adjuvante.

No ano de 2000 retornou com novas calcificações, desta vez em mama direita, diagnosticadas por biópsia ("core-biopsy") como carcinoma ductal invasivo, grau II-III, associado com carcinoma ductal in situ. Foi sugerida à paciente uma mastectomia bilateral preventiva, porém ela não concordou com o procedimento, sendo então realizada uma quadrantectomia direita com esvaziamento axilar. O tumor foi estadiado como grau II, $\mathrm{T}_{2} \mathrm{~N}_{1} \mathrm{M}_{0}$, e a paciente iniciou quimioterapia adjuvante e radioterapia.

Após o tratamento, a paciente manteve-se em acompanhamento semestral, onde todos os exames de rotina solicitados mantiveram-se dentro da normalidade até o presente momento.

É de grande importância ressaltar que a paciente apresenta um importante histórico familiar de câncer, sendo a avó paterna portadora de tumor de mama, diagnosticada aos vinte e nove anos; o pai diagnosticado com fibrossarcoma de mesentério aos quarenta e seis anos de idade e falecido no mesmo ano em que foi feito o diagnóstico; tio paterno diagnosticado aos quarenta e oito anos de idade com tumor de medula óssea; uma irmã portadora de leucemia, diagnosticada com um ano e meio e falecida aos dois anos de idade; e a outra irmã, diagnosticada com tumor de mama aos trinta e um anos e falecida um ano depois. O histórico familiar apresenta-se ilustrado no heredograma abaixo, com as respectivas idades dos familiares ao diagnóstico (Figura 1).

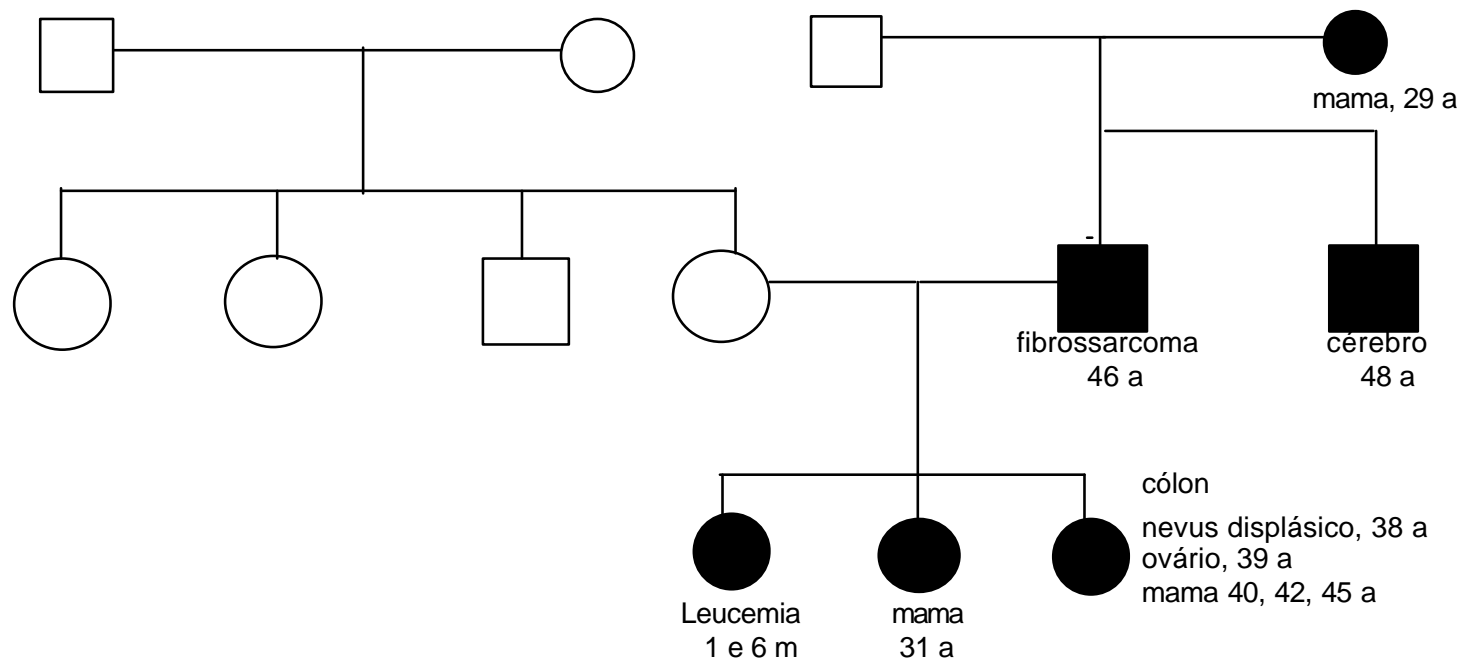

Figura 1 - Hederograma familiar. 
Devido aos múltiplos tumores primários apresentados pela paciente, juntamente com a presença de antecedentes familiares sugestivos da Síndrome de Li-Fraumeni, foi solicitado o sequenciamento do p53. Este exame (realizado pela Oncormed em Maryland, EUA) indicou a mutação no exon 5 do nucleotídeo 437 do códon 146, causando a troca do aminoácido triptofano (TGG) para uma mensagem de parada da síntese protéica (TAG) (códon de parada prematuro ou "stop-códon").

Foi contemplada a pesquisa da mutação do p53 para os familiares da paciente com história de câncer e para os filhos, a fim de investigar a presença da mutação. Tal recomendação, entretanto, não foi seguida pela paciente.

\section{DISCUSSÃO}

A Síndrome de Li-Fraumeni é uma rara síndrome autossômica dominante, que acomete aproximadamente um a cada cinqüenta mil indivíduos ${ }^{20}$. Caracteriza-se por mutações herdadas no gene supressor de tumor $p 53^{18}$ e por um fenótipo clínico de múltiplas neoplasias primárias, como tumores de mama, sarcomas de partes moles, osteossarcomas, tumores de cérebro, leucemias, linfomas, carcinomas adreno-corticais e tumores de ovário ${ }^{22}$, sobretudo em adultos jovens e crianças ${ }^{24}$.

Os tumores de mama são os de maior prevalência entre as mulheres portadoras da Síndrome de Li-Fraumeni, sendo $25 \%$ diagnosticados em mulheres abaixo dos 30 anos, e $89 \%$ em mulheres abaixo dos cinqüenta anos de idade ${ }^{9,14,18}$. Essa prevalência de tumores de mama é bastante evidente na família da paciente estudada, cuja irmã e avó eram portadoras de tumores de mama, além dela própria, que apresentou dois tumores primários em mama esquerda e um em mama direita antes de completar 50 anos de idade.

Historicamente, a caracterização da Síndrome de Li-Fraumeni ocorreu a partir do aparecimento de sarcoma em indivíduos abaixo dos 45 anos, cujos parentes de primeiro grau foram diagnosticados com algum tipo de câncer também antes dos 45 anos de idade $^{14,23}$. Curiosamente, no presente caso, o pai da paciente era portador de um fibrossarcoma, e anteriormente sua mãe e seu irmão já haviam apresentado câncer de mama e de medula óssea, respectivamente. Adicionalmente, em indivíduos acometidos pela Síndrome de Li-Fraumeni, observase alta incidência de várias neoplasias em uma mesma família, desenvolvimento multifocal de neoplasias primárias no mesmo órgão ou bilateralmente, e mesmo tipo de câncer em dois ou mais parentes de uma família ${ }^{22}$. Essas evidências clínicas são encontradas na família da paciente estudada, que apresenta uma alta incidência de neoplasias, sobretudo de mama, inclusive com a presença de mais de uma neoplasia primária no mesmo órgão e também bilateralmente.

O diagnóstico da Síndrome de Li-Fraumeni classicamente pode ser feito, portanto, a partir das evidências clínicas citadas anteriormente associadas à investigação de mutação genética, sobretudo no gene p53, através de seu seqüenciamento em um tecido não envolvido por tumor como, neste caso, o sangue periférico. É importante ressaltar, entretanto, que em alguns raros casos, mutações em outros genes podem desencadear a Síndrome de Li-Fraumeni, embora seja menos freqüente. Um exemplo é o gene CHK2, responsável pela ativação e modulação do gene $p 53^{24}$. Apesar deste fato, a mutação do gene p53 é a de maior relevância para o diagnóstico da Síndrome de Li-Fraumeni, sendo encontrada em $30 \%$ das famílias com a síndrome. Esta incidência é sugestiva de que outros fatores, ainda pouco esclarecidos, também possam contribuir para o seu surgimento, como outras alterações genéticas ou influência de fatores ambientais ${ }^{23}$.

$\mathrm{Na}$ literatura, estudos indicam que a mutação mais freqüentemente observada no gene p53 é a substituição de um nucleotídeo, geralmente resultando em uma alteração missense (troca de aminoácidos), embora, mais raramente, possa ocorrer uma alteração non-sense (códon de parada prematuro), como é o caso da paciente estudada ${ }^{20}$.

Depois de estabelecido o diagnóstico da Síndrome de Li-Fraumeni, algumas implicações práticas podem ser consideradas, visando uma melhor abordagem do paciente. Sugere-se que o acompanhamento seja feito, sempre que possível, por uma equipe multidisciplinar, a fim de aconselhar o paciente e seus familiares sobre as opções disponíveis para diminuição do risco de futuros tumores, como profilaxia cirúrgica e quimioprevenção².

A prevenção de tumores nestes casos pode ser feita de três formas ${ }^{22}$ : prevenção primária (prevenção de um câncer primário em indivíduo saudável com alto risco como, por exemplo, a cessação do tabagismo); prevenção secundária (tratamento ou reversão de uma lesão pré-maligna, como o uso de retinóides em lesões pré-malignas de cabeça e pescoç $0^{15}$ ) e prevenção terciária (prevenção de um segundo câncer primário em indivíduo previamente curado de câncer, como no caso do uso de tamoxifeno em mulheres com história prévia de câncer de mama in situr5). Todas estas medidas podem ser adotadas na abordagem do paciente, bem como de seus familiares, de acordo com a indicação médica específica para cada caso. 
A profilaxia cirúrgica é direcionada, sobretudo, à diminuição da incidência do câncer, embora raramente seja capaz de reduzir a risco zero. É importante esclarecer aos pacientes o impacto potencial que esse procedimento pode ter em sua saúde geral, e o risco da existência de um tumor residual22.

Além das implicações clínicas, é de fundamental importância considerar as implicações éticas na abordagem do paciente portador da Síndrome de Li-Fraumeni. Um exemplo disto é a dúvida em relação à notificação dos demais parentes da presença da síndrome e quanto à própria realização ou não do sequenciamento do p53 nos filhos e familiares da paciente, podendo desencadear uma sensação de culpa em transmitir a mutação aos filhos, que serão obrigados a conviver com a espera angustiante de uma provável doença iminente ${ }^{8}$. $\mathrm{Da}$ mesma forma, a configuração de doença préexistente pode ter importantes implicações para efeito de seguro médico da paciente e de seus familiares. A pesquisa científica deve utilizar seus resultados a favor de minimizar a ansiedade dos indivíduos e não de provocar angústias diante da possibilidade de uma doença geradora de medo ${ }^{1}$.

Antes da realização do sequenciamento do p53 os indivíduos devem ser informados a respeito de como será sua vida após um eventual resultado positivo (exames a serem realizados periodicamente, possibilidades terapêuticas disponíveis, possíveis riscos de erro no método de investigação) ${ }^{2}$. À medida que a tecnologia avança no sentido de um diagnóstico mais freqüente dessa síndrome, o treino de profissionais da área oncológica para aconselhar e orientar estas famílias para a prevenção e detecção precoce de tumores é prioritário.

\section{CONCLUSÃO}

Este caso ilustra a Síndrome de Li-Fraumeni do ponto de vista clínico e molecular, com o intuito de difundir em nosso meio o conhecimento desta entidade e de suas implicações clínicas, éticas e relacionadas à prevenção.

Pinto FN, Prudente FVB, Gonçalves MS, Silva PDV, Giglio A. P53 gene mutation inducing hereditary cancer predisposition: case report of Li-Fraumeni syndrome. Rev Med (São Paulo) 2002 jan./dez.;81(1/4):42-6.

ABSTRACT: Li-Fraumeni syndrome is a familiar cancer predisposition syndrome characterized by the appearance of various types of tumors, such as sarcomas, breast carcinomas, brain tumors and leukemia. We present the case of a 37-year-old female who had a strong family history of cancer and herself had a history of six different primary tumors (one colon, one displasic nevus, one ovary and three breast tumors). P53 gene sequencing of her peripheral blood lymphocytes revealed an amino acid change of tryptofan (TGG) to a stop-codon (TAG) in the nucleotide 437 of codon 146 of exon 5 of this gene. Clinical, preventive and ethical implications of this molecular finding are also discussed.

KEYWORDS: Neoplasms multiple primary/genetics; P53 Protein/genetics; Mutation/genetics.

\section{REFERÊNCIAS}

1. Boff RA. Genética e câncer de mama: entusiasmo e realidade. Rev Bras Mastol 1996;6:109-10.

2. Braz M. O diagnóstico genético do câncer de mama e a ética. J Bras Ginecol 1997;107:273-9.

3. Cotran RS, Kumar V, Collins T. Robbins patologia functional e estrutural. $6^{\text {a }}$ ed. Rio de Janeiro: Guanabara Koogan; 2000. p.261.

4. Dirks PB, Rutka JT. Current concepts in neurology: the cell cycle a review. Neurosugery 1997;40:1000-15.

5. Elledge RM, Lee WH. Life and death by $\mathrm{p} 53$. Bioessays 1995;11:923-30.

6. Evans SC, Lozono G. The Li-Fraumeni syndrome: susceptibility to cancer. Mol Med Today 1997;3:390-5.

7. Fearon ER, Vogelstein B. A genetic model for colorectal tumorigenesis. Cell 1990;61:759-67.

8. Greely HT. Ethical and legal issues associated with genetic testing. J Am Coll Surg 1999;188(1):86-9.

9. Hartley AL, Birch JM, Malsden HB, Harris M. Brest cancer risk in mothers of children with osteosarcoma and chondrosarcoma. Br J Cancer 1986;54: 819-23.

10. Lane DP. P53 and human canceres. Br Med Bull 1994; 50:582-99.

11. Lane DP. P53, guardian of the genome. Nature 1992; 358:15-6.

12. Levine AJ, Momand J, Finlay CA. The p53 tumor supressor gene. Nature 1991;351:453-6.

13. Levine AJ. P53, the cellular gate keeper for qrowth and division. Cell 1997;88:323-31. 
14. Li FP, Fraumeni JFJr, Mulvihill JJ, Blattner WA, Dreyfus MG, Tucker MA, et al. A cancer family syndrome in twenty-four kindreds. Cancer Res 1988;48:5358-62.

15. Lippman SM, Benner SE, Hong WK. Retinoids in chemoprevection of head and neck carcinogenesis. Prev Med 1993;22(5):693-700.

16. Ljungman M. Dial 9-1-1 for p53: mechanisms of $p 53$ activation by cellular stress. Neoplasia 2000;2:20825.

17. Lohman D, Ruhri CH, Schmitt M. Acumulation of p53 protein as an indicator for p53 gene mutation in breast cancer. Diagn Mol Pathol 1993;2:36-41.

18. Malkin D, Li FP, Strong LC, Fraumeni JFJr, Nelson $\mathrm{CE}, \mathrm{Kim} \mathrm{DH}$, et al. Germ line mutations in a familial syndrome of brest cancer, sarcomas and neoplasms. Science 1990;250:1233-8.

19. Poller DN, Ellis IA. Oncogenes and tumor morphology prediction. Mod Pathol 19930;6:376-7.

20. Robson ME, Boyd J, Borgen PF, Cody HS. The genetics of hereditary brest cancer. Curr Probl Surg $2001 ; 38(6): 387-480$.

21. Snaw $\mathrm{PH}$. The role of $\mathrm{p} 53$ in cell cycle regulation. Pathol Res Pract 1996;192:669-75.

22. Swisher E. Hereditary cancers in obstetrics and gynecology. Clin Obstet Gynecol 2001;44:450-61.

23. Tonin PN. Genes implicated in hereditary brest cancer syndromes. Semin Surg Oncol 2000;18:281-6.

24. Vahteristo $P$, Tamminen $A$, Karvinen $P$, Eerola $H$, Eklund C, Aaltonen LA, et al. P53, CHK2, and CHK1 genes in finnish families with Li-Fraumeni syndrome: further evidence of $\mathrm{CHK} 2$ in inherited cancer predisposition. Cancer Res 2001;61:5718-22.

25. Vogel VG. Breast cancer prevention: a review of current evidence. CA Cancer J Clin 2000;50(3):156-70. 